\title{
Knowledge, Discipline, System, Hope The Fate of Metaphysics in the Doctrine of Method
} Andrew Chignell ${ }^{*}$

We always return to metaphysics as a beloved from whom we have been estranged.

$-A 850 / B 878$

\section{I4.I Kant's Plan}

Despite being dwarfed by "The Transcendental Doctrine of Elements" in both size and influence, "The Transcendental Doctrine of Method" is officially the second main part of the Critique of Pure Reason. It starts with an architectural metaphor: in the first part of the book, Kant says, we "made an estimate of the building materials and determined for what sort of edifice, with what height and strength, they would suffice" (A707/B 735 ). Those materials came from both sensory intuition (Transcendental Aesthetic) and conceptual understanding (Transcendental Analytic). But although "we had in mind a tower that would reach the heavens," it turned out that speculative a priori reasoning did not offer legitimate materials for the purposes of either knowledge or science (Transcendental Dialectic).

In this slender second part of the Critique Kant turns from estimating materials to developing "the plan." The goal is to avoid the fate of the architects at Babel by constructing "an edifice that is in proportion to the supplies given to us and at the same time suited to our needs." In other words, the goal is to rejoin the general human project of trying to understand the world - a project "from which we are not able to abstain" - while taking into account what we have discovered about the nature and limits of our cognitive materials (A707/B735).

* For feedback on earlier drafts, I'm grateful to the people mentioned in the notes to follow, as well as to Karen Bennett, Angela Breitenbach, Susan Brower-Toland, Alix Cohen, Everett Fulmer, Don Garrett, John Greco, Desmond Hogan, Anja Jauernig, Béatrice Longuenesse, Michela Massimi, Tyke Nunez, Michael Oberst, Jim O’Shea, Konstantin Pollok, Erica Shumener, Ted Sider, and Eric Watkins. 
This way of characterizing the plan - i.e., both negatively and positively - is typical of the entire Critique, but especially of this second part. On the one hand, we have to keep in mind the newfound limits of our materials, and thus "discipline," "censure," "humiliate," "caution against," "constrain," "compel," and even "extirpate" the illicit urge (often arising from reason itself) to construct an edifice for which our building materials are not adequate (see e.g., A708-II/B $736-40$ ). On the other hand, we have to acknowledge our needs as rational, inquiring beings who "lust after knowledge" and "speculative expansion" (A708/B736), who seek "the therefore to every wherefore" ( $z$ u allem Warum das Darum) (A585/B6r3) and thus always "return to metaphysics as to a beloved from whom we have been estranged" (A850/B878). We also have to acknowledge our needs as sensory, moral beings: for most of us, virtue does not suffice as its own reward: we need some reasonable way to hope for individual happiness and collective justice if we are to avoid becoming demoralized as agents.

The Doctrine of Method is divided into four chapters: "The Discipline of Pure Reason," "The Canon of Pure Reason," "The Architectonic of Pure Reason," and "The History of Pure Reason." Each is about half the size of its predecessor, and reading through all four gives the impression of an author who was running out of time, steam, or both. In this paper, I will set aside the "History" chapter, which comprises a three-page sketch of the developments leading up to the critical philosophy, and focus instead on the first three chapters.

After providing Kant's positive account of knowledge (Wissen) in the Canon, I go on to discuss the prohibition (in the Discipline) against synthetic knowledge claims regarding "supersensibles" - i.e., those things of which we cannot have any sensible experience per se. My main proposal is that, from the I76os onward, Kant held that objects have a modal status - their "real" modal status - that is more restrictive than their merely "logical" modal status. But by I78I, Kant had also come to reject the Cartesian-rationalist idea that we have a faculty of clear and distinct perception that can tell us what is really, metaphysically possible. Naturally we can still think up all sorts of nonactual beings, but such thought merely tracks the wider domain of logical possibility. As a result, we cannot rule out the concern that in speculative contexts we are thinking up concepts of objects souls, God, freedom, or monads, for instance - that are logically possible but still really impossible. Without the ability to rule this out, Kant concludes, we must restrict knowledge claims to propositions whose really possible truth we can in some way "justify" (rechtfertigen) (A259/B 315$)$. 
If the proposal is accurate, then the modal condition that we be able to "justify" the real possibility of the objects we claim to know is more fundamental than, and even motivates, the empiricistic demand that an object of knowledge be "given" to the mind via some sort of relation to intuitional experience. In the Discipline, Kant argues that analytic judgments, mathematical judgments, and the transcendental judgments of the critical philosophy itself can satisfy this modal condition, but that the synthetic claims of "dogmatic" metaphysics cannot. In the Architectonic, Kant gives us a further clue about what it would be to meet the condition: we must be able to "prove" (in a way to be discussed below) that a proposition's truth systematically coheres with our background knowledge. In effect, then, I submit that Kant embraces what contemporary epistemologists call a "coherentist" constraint on knowledge, one that is based in our antecedent grasp of nature and its laws.

At the end of the paper, I return to the Canon and look briefly at the way in which Kantian "hope" (Hoffnung) satisfies the rational needs that the Discipline quashes in the epistemic sphere. The word "hope" appears far more frequently in the Doctrine of Method than in other parts of the book. Kant's use of it highlights his two-part message: dogmatic metaphysicians should abandon all hope, but the new critical "metaphysics of experience" offers hope for a new way forward. It also leaves room for rational hope and even belief (Glaube), though not knowledge, regarding at least some of the paradigmatic objects of traditional metaphysics.

\subsection{Knowledge and the Canon}

In order to grasp the account of knowledge (Wissen) in the Canon, it is important to recognize that Kant's conception of the fundamental positive propositional attitude differs from our contemporary Anglophone concept of belief and its contemporary German equivalent, Überzeugung. For Kant the fundamental attitude is that of holding-for-true (Fürwahrhalten) - a term often translated into English as "assent."

Kant describes Fürwahrhalten in the Canon as a state that "may rest on objective grounds (Gründen), but that also requires subjective sources (Ursachen) in the mind of him who judges" (A820/B848, my emphasis). The character of a particular assent, in other words, is determined both by its subjective features (how firmly the assent is held, what the subject takes it to be based on) and by its objective features (how probable the proposition is on those grounds, whether the assent was appropriately caused, 
etc.). We might hold a proposition weakly as a mere opinion (Meinung), for example, if we acknowledge that we have some limited grounds for it (most hypotheses, for instance, count as opinions). We can also hold a proposition for true in a firm way but for self-consciously "subjective" reasons as a matter of belief (Glaube). Finally, we can hold a proposition for true in a "sufficient" (zureichend) manner from both a subjective and an objective point of view - in that case, it counts as knowledge (Wissen) (A822/B850).

I've analyzed the notions of objective and subjective "sufficiency" elsewhere and won't try to reproduce the account again here (see Chignell

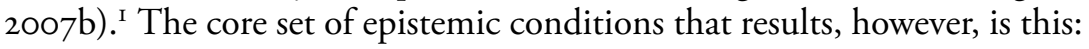

Knowledge (Wissen): S's assent that $p$ counts as knowledge only if $(\exists g)$ such that

(i) $g$ is an objectively sufficient ground that $S$ has,

(ii) $S$ 's assent that $p$ is based on $g$,

(iii) $p$ is true, and

(iv) $g$ is subjectively sufficient - i.e., on reflection, $S$ would cite $g$ as her objective ground for the assent that $p$.

Conditions (i), (ii), and (iii) are "external" constraints: the assent must be based on what are in fact sufficient grounds that $S$ has in her possession, and the assent has to be true. ${ }^{2}$ By contrast, (iv) articulates an "internal" constraint, albeit a very weak one. It says that, for example, if $S$ knows that the rabbit is presently in the garden, $S$ has to be such that, if she were asked why she holds that, she would reference (or "cite") her visual experience of the rabbit and the garden (or testimony, or induction, or some other objectively good ground for that assent). ${ }^{3} \mathrm{~S}$ does not have to be able to say why that experience is a sufficiently good objective ground for the assent, how likely the ground renders the assent, and so forth. That's what makes the constraint both internal and weak (and plausible!).

People familiar with the Critique may wonder at this point whether there is an important condition missing, one that expresses Kant's conviction, in the Doctrine of Method and throughout, that substantive knowledge must be grounded in intuition:

\footnotetext{
I See also Stevenson (2003) and Pasternack (20I4a).

2 I favor a "fallibilist" or "defeasibilist" picture according to which all the other conditions for knowledge could be met apart from (iii) and the assent still turn out to be false (see Jäsche Logic 9:72 LL 575-76, for instance). For indefeasibilist readings, see Makkreel (2003) and Pasternack (2014a).

3 See, for example, Kant's talk of a subject being "in a position to make a supposition" about whether a given ground is an objectively good one (Blomberg Logic 24:87-88, LL 66-67). For Kant on testimony, see Gelfert (2006).
} 
All of our cognition is in the end related to possible intuitions: for through these alone is an object given. (A719/B 747 ; compare $\mathrm{A}_{286}$ /B342)

The proposed condition would be something like

(v) $g$ bears an appropriate relation to a possible intuition (pure or empirical).

As stated, this is too vague: if the ground of assent, $g$, just is an intuition, or is partly constituted by intuition, then the condition is presumably met. But what other relations to intuition count as "appropriate"? Can we make knowledge-preserving inferences from what we do intuit to what we could intuit? Or to unobservables? What about inferences from a structural feature of intuition to its transcendental conditions - do those relations count as appropriate? What does "givenness" amount to here, and why is intuition so important - isn't the relevant thing just the character of the justifying ground, no matter what its source? In other words, why do we need a condition like (v) if we've already got (i)?

I will return to these questions below. For now, it is worth noting that (v) as stated won't do as a necessary condition on knowledge simpliciter. For Kant's claim in the quotation here is about cognition (Erkenntnis) rather than knowledge (Wissen), and elsewhere he explicitly allows that there is some knowledge that is not based in cognition or related to possible intuition in any interesting way. For example, well-formed analytic judgments allow us "to know what lies in the concept" (wissen, was in seinem Begriffe liegt) $\left(\mathrm{A}_{259} / \mathrm{B}_{315}\right)$, but aren't necessarily based in intuitions of the objects of the concepts (I don't have to perceive any bachelors in order to know that they're all male). In speculative contexts, moreover, some of the concepts will pick out things-in-themselves (God, the soul, free wills, monads, etc.) - and thus supersensibles of which we can't have intuition. But surely Kant would allow (under threat of performative contradiction, given all those lectures on metaphysics and philosophical theology) that we have some analytic knowledge of their contents.

Similarly, we might know about a domain of things in a wholly negative fashion without having intuition of those things - consider here the assent that things-in-themselves are not in space and time. The objectively sufficient grounds of such knowledge might be Kant's transcendental arguments establishing that space and time are the mere forms of our receptive sensible intuition, together with the fact that things-in-themselves are, by definition, supersensible (see B307). As we will see, Kant suggests in places that we have positive but very general knowledge about such things - that 
things-in-themselves exist and ground appearances, for example (Prol. 4:314I5, $T P_{2}$ I07-8). But any such negative or very general positive knowledge about things-in-themselves will not be based in cognition or intuition of those things (see Bi49).

There is more to be said about these cases, but this suggests that, for Kant, there is some knowledge that is not related to actual or possible intuition in an epistemically significant way. It also emphasizes the need to find a revised version of $(\mathrm{v})$ that is adequate to such cases and yet allows us to preserve a unified account of Kantian knowledge. Ideally, the revised version would also explain Kant's claims about the importance of intuition as well as his prohibition on synthetic knowledge claims about the positive characteristics of specific things-in-themselves.

\section{I4.3 Ignorance and the Discipline}

A familiar thought comes to mind at this juncture: Kant often says that our concepts of supersensibles are "useless" in epistemic contexts because "concepts without intuitions are empty." In other words, it's not that the inferences in speculative arguments are always invalid (though some of them clearly are), or that one of the premises must be false, but rather that some of the concepts lack the right kind of content (see, e.g., A62/B87; Bi48; A220/B267). ${ }^{4}$ Without a connection to possible intuition, Kant says in the Discipline, we risk "basing our reasoning on empty figments of the brain rather than concepts of real things" (A770/B798). He often uses hylomorphic images to describe what he has in mind: the "form" of our concepts has to be connected to the "matter" of intuition in order for us to be sure we're not merely groping among "thought-entities" (Gedankenwesen) or "playing with fancies instead of concepts and words instead of things" (A710/B 738 ; see also A723/B75I, A77I/B799, and A239/B298).

This talk of emptiness, brain-figments, matter, and groping is clearly metaphorical. No serious rationalists - old- or new-fangled - will find it persuasive on its own, nor will they accept a bald stipulation that concepts without a connection to possible intuitions have no epistemic use. Some

4 Regarding his own theistic proof from 1763 , for instance, the Critical Kant says that "this proof can in no way be refuted (allein widerleget kann er aufkeine Weise werden), because it has its ground in the nature of human reason. For my reason makes it absolutely necessary for me to accept (annehmen) a being which is the ground of everything possible, because otherwise I would be unable to cognize (erkennen) what in general the possibility of something consists in" (LRel 28:IO34, RRT 375). The "acceptance" here is what he calls, in the Canon, "doctrinal belief" (see below for more discussion). 
commentators seem willing to take the demand for intuitional "matter" here as indicative of a broadly empiricist commitment that Kant adopted after Hume woke him from his slumbers, and leave it at that. ${ }^{5}$ But why did he go in that direction? What was the root concern? Why must our concepts, as well as the assents that involve them, be related in some way to intuition? And, again, which kinds of relation are appropriate?

A related line of thought is this: in order to claim knowledge about any object at all, we have to have some sort of mental grasp of or reference to that object. Perhaps this is what Kant means when he repeatedly demands that objects be "given" to the mind and that concepts without intuitions are "without sense or reference" (AI55-56/Bi94-95; A72I/B729). But again, why must the "giving" occur by way of a relation to actual or possible intuitions, rather than by simply generating and entertaining concepts? When Descartes entertains the idea of God or an immaterial soul in Meditations, he surely has some sort of mental grasp of what he is discussing. But then why aren't those things "given" to him in the relevant sense? To insist that mental "givenness" just has to go by way of a connection to intuition again looks merely stipulative. ${ }^{6}$

I think we can go beyond metaphors and stipulations by viewing Kant's prohibition on synthetic knowledge of particular supersensibles as arising more organically out of his lifelong reckoning with his rationalist predecessors. Here's the story in brief: 7 in the 1760 , Kant spied a metaphysical difference between "logical" possibility and real possibility; he also saw the related point that there can be "real opposition" (reale Entgegensetzung) or "real repugnance" (Realrepugnanz) between logically consistent positive

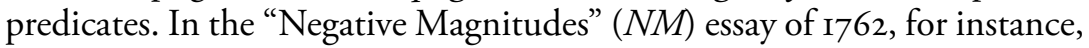
he cites the example of two equally powerful winds blowing from opposed directions on a sail: they "cancel out" (aufheben) one another, and the ship remains at rest $\left(N M\right.$ 2:I7I, $\left.T P_{I} 2 \mathrm{II}\right)$. In that essay as well as in The Only Possible Argument (OPA) of the following year, Kant also mentions cases of subject-canceling rather than merely predicate-canceling real opposition. This form of real opposition doesn't merely cancel out the effects of the predicates involved; rather, it "cancels" the subject altogether. One of Kant's

\footnotetext{
5 A. W. Moore points out that Kant first uses the "awakening" metaphor in connection with Hume here in the Discipline at A764/B792 (Moore 20IO).

${ }^{6}$ For more on "givenness" and cognition, see Watkins and Willaschek (2017), Grüne (2017), and Chignell (20I7).

7 See Chignell (20II, 20I4a) for a longer version of the story, and Abaci (20I4) and Yong (2014) for objections to it.
} 
examples is that "the impenetrability of bodies, extension, and the like, cannot (können nicht) be properties of what has understanding and will." It's not that being impenetrable and having understanding are logically inconsistent: there is no way to generate a contradiction from their conjunction using standard rules and definitions. Rather, it's that "these predicates can by no means co-exist together as determinations in a single subject" (nimmermehr in einem einzigen Subject als Bestimmungen neben einander können statt finden) (OPA 2:85, 130, my emphasis). The 'cannot' and 'can' in these sentences clearly express real rather than logical modalities: Kant thinks there simply cannot be a subject that is both a body and has understanding.

By the time of the Critique, Kant regarded the rationalists' alleged neglect of these nonlogical constraints on possibility as a serious mistake. In the "Phenomena/Noumena" chapter, for example, he points out that the real possibility of something cannot be established by mere thinking:

That the not-being of a thing does not contradict itself is a lame appeal to a logical condition, which is certainly necessary for the concept but far from sufficient for real possibility. (A244/B302, my emphasis)

He laments in the Amphiboly that with respect to the concept of a supreme being, for instance, the rationalists

find it not merely possible but also natural to unite all reality in one being without any worry about opposition, since they do not recognize any opposition except that of contradiction. (A273-74/B229-30)

The mistake here is modal: when Leibniz and Wolff seek to demonstrate the existence of a supreme being through armchair speculation, they just presume, as Kant puts it in a lecture, that they have "insight (Einsicht) into whether all realities could be united together in one object (Objekt), and hence into how God is possible" (LRel 28:1025-27, RRT 368-69, my emphasis). ${ }^{8}$ But, again, if there are nonlogical, real constraints on possibility - constraints that can't reliably be tracked via mere thought then that presumption looks hasty. For all we know, in such a speculative

8 Other cases of predicate-canceling real impossibility are found in the Metaphysical Foundations of Natural Science $(M F)$. For instance, "two motions" that are "combined in precisely opposite directions in one and the same point" are such that they cancel the entire subject to which they are ascribed: " $[R]$ epresenting two such motions at the same time in exactly the same point within one and the same space would be impossible, and thus so would the case of such a composition of motions itself" $\left(M F\right.$ 4:49I, $T P_{2}$ 203-4). Another example: a material being "is impossible if it has mere attractive forces without repulsive forces," and this impossibility has its basis in "the essence of matter" rather

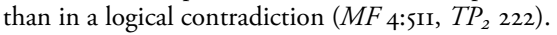


context, the concept includes predicates that are really opposed in such a way as to cancel out the subject itself - that is, to make it really impossible.

It is in direct response to these metaphysical and epistemological concerns about rationalist modal theory, I submit, that Kant develops his fifth epistemic condition. "I can think whatever I like," he says in the B-Preface,

as long as I do not contradict myself, i.e., as long as my concept is a possible thought, even if I cannot give any assurance as to whether or not there is a corresponding object [Objekt] somewhere within the sum total of all [real] possibilities.... [But] to cognize an object, it is required that I be able to prove its [real] possibility (whether by the testimony of experience from its actuality or a priori through reason)" (Bxxvin).

This passage is focused on cognition, but the few kinds of knowledge that are not based in cognition can easily meet this modal condition. In analytic contexts, the relevant "objects" are just the concepts we are analyzing, ${ }^{9}$ so if we can "prove" that the concepts themselves are actual (by being aware that we have them), then we can a fortiori prove that they (though not necessarily their objects) are really possible. ${ }^{\mathrm{I}}$

If the synthetic but very general assent that things-in-themselves exist and ground appearances counts as knowledge, then we can find "proof" of their (or its) real possibility in the fact that their (its) actual existence is a condition of the existence of any appearances at all. In the Preface, Kant seems to go this direction: he says it would be "absurd" for there to be appearances without there also being something that appears, i.e., something that grounds those appearances (Bxxvi). In the Prolegomena, he says, similarly,

The understanding, just by the fact that it accepts appearances, also admits to the existence of things in themselves, and to that extent we can say that the representation of such beings as underlie the appearances, hence of mere intelligible beings, is not merely permitted but also unavoidable. (Prol. 4:315, $T P_{2}$ I07; see also Prol. 4:355, $T P_{2}$ I44)

Commentators disagree about whether this is supposed to be self-evident, or a conceptual truth, or a quick deductive inference, but many follow Erich Adickes in holding that it provides a "proof" of the actuality (and thus real possibility) of noumenal grounds taken collectively, though not

9 "For an analytic assertion takes the understanding no further, and since it is occupied only with that which is already thought in the concept, it leaves it undecided whether the concept even has any relation to objects...; it is enough for [the subject] to know (wissen) what lies in the concept; he is indifferent to what the concept might pertain to" (A 258-59/B 314).

Io "That the concept (thought) is possible is not an issue; the issue is rather whether it relates to an object and therefore signifies anything" (B 302-3n). 
of any specific, determinate thing (monad, deity, soul, etc.) among them. ${ }^{\text {II }}$ Any negative knowledge about the same objects, such as that things-inthemselves are not in space and time, would presumably be based on the same "proof" as well as Kant's transcendental reflections about the nature of space and time.

Since the modal condition here obviously applies to all knowledge that is based in cognition and, as we have seen, to the few kinds of noncognitional knowledge that Kant seems to allow, it is a nice candidate for a revised version of the fifth condition on knowledge. Here is a first stab:

$\left(\mathbf{v}^{*}\right): S$ is in a position to prove the real possibility of the objects referred to in $p$.

A remaining problem with this is that we clearly know, about impossible objects, that they are impossible. For instance, we know that intersecting parallel lines cannot exist. Kant says that in such cases "the impossibility rests not on the concept itself but on its construction in space, i.e., on the conditions of space and its determinations" (A22O-2I/B268; cf. A224/B27I). This indicates that the modality in such a case is real rather than merely logical, and that the "proof of possibility" that Kant has in mind is something more like proof of whether or not the objects referred to are really possible (think of phrases like "prove your mettle" or "proof of the pudding" - we test for the presence of a certain property rather than proving that the property is positively there). This suggests the following revision:

$\left(\mathbf{v}^{* *}\right)$ for any object referred to in $p$, if it is really possible then $S$ is in a position to prove its real possibility, and if it is really impossible then $S$ is in a position to prove its real impossibility.

More work would be required to go beyond propositions with atomic structure, ${ }^{\text {I2 }}$ but for now I propose to take $\left(\mathrm{v}^{* *}\right)$ as a good approximation of Kant's fifth condition on knowledge.

II Adickes took this belief in the existence of things in themselves to be simply "self-evident" for Kant (see Adickes [1924] and the extensive discussion of it in Bird [2006: Chapter 23]). Some commentators want to avoid interpreting this or any other text as licensing a synthetic existence-claim about things-in-themselves (Bird 2006: 42-44, 559-63; cf. O'Shea 20I4: IO6-I5). If they are right, then the modal condition I'm developing here would be in even better shape, since cognition is clearly governed by a modal condition for Kant.

12 We would need to know, for instance, about knowledge of (a) conditionals (I can know that "if there are unicorns, then there are horns" is true without proving that unicorns are really possible), (b) negations (I can know that "it's not the case that there is a golden mountain in the room" without proving that golden mountains are really possible or impossible), and (c) disjunctions (I can know that "I am writing a paper or God is a deceiver" without proving that God is really possible). My sense is that (a) can be assimilated to conceptual or broadly analytic knowledge that is about the concepts rather than the objects of those concepts, (b) can be interpreted as about the room and the items in it, rather than about the golden mountain, and in (c) only the disjunct that makes the entire disjunction true has to meet the modal condition. 


\section{I4.4 Possibility and the Postulates}

At this point, the obvious question is: well, what sort of "proof" or "justification" of real possibility is available? Three different strategies emerge in Kant's discussions in the Discipline and, more expansively, in the "Postulates of Empirical Thought" (the chapter on modality).

\section{I4.4.I First Strategy: Appeal to Actuality}

According to Locke, if we propose to combine some qualities in the complex idea of some substance or kind, we must actually experience the individual qualities and their combination. Without such actual experience, according to Locke, we can't be sure that the qualities are not "in-co-existent" (Locke's term: Essay 4.3.I2). This is part of what leads him to the doctrine that things may have real essences that ground the "strict union" of all sorts of qualities that we haven't experienced at all - or haven't experienced together - but that a good empiricist will restrict her knowledge claims to propositions about nominal essences that contain qualities which "we can be sure are, or are not, inconsistent in Nature." And the only way she can be sure of that is by appeal to "Experience and sensible Observation" (Essay 4.4.12).

In places, Kant sounds downright Lockean on this question:

In a word, all of these concepts could not be vouched for (belegen) and their real possibility thereby established (dartun), if all sensible intuition (the only one we have) were taken away, and there then remained only logical possibility. (B302-3n)

Now, however, the possibility of a thing can never be proved (bewiesen werden) merely through the non-contradictoriness of a concept of it, but only if is vouched for (belegt) by an intuition corresponding to the concept. (B308)

The appeal to intuition works in some a priori contexts as well: in the Discipline, Kant emphasizes that many mathematical judgments satisfy the modal condition by appealing to intuitive "constructions" of their objects in pure intuition. Such construction proves their actuality, and that trivially entails their real possibility (see A718/B746).

\subsubsection{Second Strategy: Appeal to Formal Possibility}

Elsewhere in the Discipline, though, Kant seems willing to allow that we can prove real possibility in ways that do appeal to actual experience. One strategy involves appealing to the "conditions of possible experience": 
In a word: our reason is only able to use the conditions of possible experience as conditions of the possibility of things (Sachen); but it is by no means possible for us as it were to create new ones independent of those conditions, for concepts of the latter sort, although free of contradiction, would nevertheless also be without any object (Gegenstand). (A77I/B799; see also A602/B630, A6ro/B638)

In order to understand this claim, we need to look at the account of the category of possibility that Kant provides in the "Postulates" chapter:

[Formal Possibility:] That which agrees (übereinkommt) with the formal conditions of experience (according to intuition and concept) is possible. (A218 /B265)

What is formally possible, in other words, is what agrees with the axioms of space and time ("according to intuition") and the principles derived from the categories ("according to concept") - in particular the Analogies of Experience. The latter principles state that all objects of our experience must be persisting substances whose states are nomologically determined and which stand in dynamic relations with all other such substances. ${ }^{\mathrm{I3}}$

Although this definition of formal possibility is relatively clear, Kant's illustrations of how it operates are obscure. With Swedenborg and other enthusiasts in the background, he mentions concepts like that of

[Ghostly Matter]: a substance that is persistently present in space yet without filling it, or

[Soothsaying]: a special fundamental power of our mind to intuit the future (not merely, say, to deduce it), or

[Telepathy]: an ability of the mind to stand in a community of thoughts with other men (no matter how distant they may be).

These concepts may be logically consistent, Kant says, but they

are concepts the possibility of which [i.e., the real possibility of whose objects] is completely baseless, because it cannot be grounded upon experience and the laws [of experience] with which we are acquainted (auf Erfahrung und deren bekannte Gesetze gegründet werden kann), and without this is an arbitrary combination of thoughts that, although it contains no contradiction, still can make no claim to objective reality, thus to the [real] possibility of the sort of object that one would think here. (A223/B270, my emphasis) ${ }^{\mathrm{I}}$

${ }^{13}$ For versions of the taxonomy of kinds of modality here, see Chignell (20Iob, 20II), Abaci (2016), Chignell and Stang (2015), Kannisto (2013), Leech (2014), and Stang (2016).

I4 This quotation is from the Postulates, but Kant cites the same examples in the Discipline at A77o/B798, and goes on to say that they are "mere thought-entities, the [real] possibility of which is not demonstrable, and which therefore cannot be used to ground the explanation of actual appearances" (A771/B799). 
It is not obvious what is meant here by "grounded upon the laws of experience with which we are acquainted." Given the definition of possibility just offered, it seems that Kant might mean in agreement with the formal conditions of experience. But then it is unclear how all of the ghostly phenomena Kant mentions would fail this test. Telepathy, in particular, seems like a hard case: the existence of such a faculty is clearly compatible with the formal axioms of space and time, and it is hard to see how it would be ruled out by the principles of the understanding (such as the Analogies).

Building more of the laws of nature into the formal conditions might be thought to help here. Perhaps, for instance, we can take the first Analogy to demonstrate that all outer objects of experience are composed of persisting extended, space-filling matter - matter that is not, thus, ghostly. ${ }^{15}$ In Metaphysical Foundations of Natural Science (1786, MF), Kant himself seems to try to underwrite more substantive claims about matter and mechanical laws by appeal to formal contributions of the mind as well as a priori "construction." But this strategy won't provide proof of real possibility in all cases. For Kant makes it clear in the B-edition Critique, written after the Metaphysical Foundations, that most of the laws of nature are "particular," i.e., not part of the formal "constitutive a priori" contribution of the mind:

Particular laws, because they concern empirically determined appearances, cannot be completely derived from the categories, though they all stand under them. Experience must be added in order to know particular laws at all. (Bi65; see also A206/B 252; A 222/B 269; CJ 5:I79-80)

So even if we can prove a priori that ghostly matter is formally impossible by appealing to the robust principles of "the metaphysics of corporeal nature" $\left(M F\right.$ 4:472, $T P_{2}$ I87), telepathy as well as many other events and objects may "agree" with the formal principles but still be really impossible given how nature actually is. This leads to a third sort of strategy, one that falls between the two just considered.

\section{I4.4.3 Third Strategy: Appeal to Empirical Possibility}

The third strategy invokes a modal notion that can be derived from the definition of necessity that Kant offers in the same "Postulates" chapter:

Is This reflects an amendment to the position in Chignell (20I4b), from which I have drawn some of the present discussion. I am grateful to the editor of that journal for permission to reuse this material here. 
[Empirical necessity:] That whose connection with the actual is determined according to universal conditions (bestimmt nach allgemeinen Bedingungen) on experience is (i.e. exists) necessarily. (A218/B266)

The "universal conditions on experience" are thicker or more "particular" than the merely formal conditions referred to in the definition of possibility, as Kant's discussion goes on to indicate. Any object (or change of state) that is connected to actual events via the formal conditions or the much more particular "empirical laws of causality" counts as necessary in this sense (see A 227/B 280). It thus seems appropriate to call this kind of necessity empirical. We can then define a counterpart conception of possibility:

Empirical possibility: Something is empirically possible iff it is not empirically necessary that it is not the case. In other words, an object or event is empirically possible iff its existence agrees with the universal conditions on experience -i.e. the formal conditions plus the particular laws and preceding actual events.

Figure I4.I provides a depiction of the various concentric modal domains, from the very broad domain of logical possibility all the way down to empirical actuality. The telepathy example is what motivates the need to make the rather ugly space for things that are formally possible but not

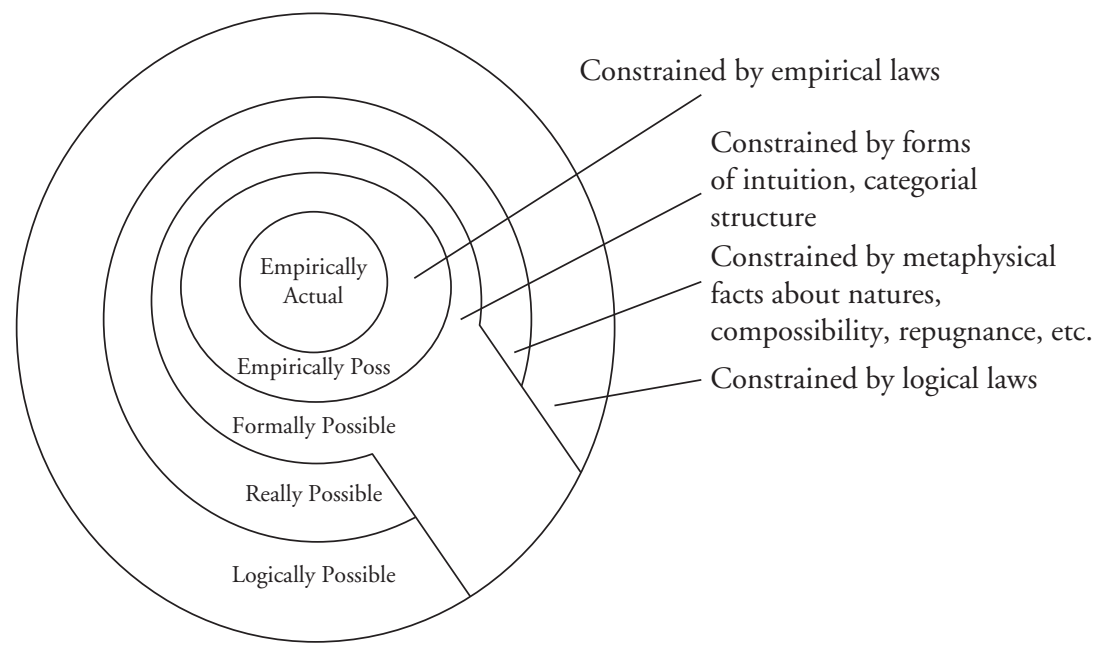

Figure I4.I 
really possible. And any existing things-in-themselves are logically and really possible but not empirically possible or empirically actual. So the diagram would have to be more complex (and three-dimensional) in order to represent their modal status. ${ }^{16}$

With this picture of the modal situation in the background, consider now the following account of what it would be to be able to "prove" real possibility:

Third strategy: $S$ is in a position to prove the real possibility of an object if $S$ is in a position to prove its empirical possibility. ${ }^{17}$

This specifies the correct modal domain, I think, but we still haven't said much about what it would mean to "prove" such a thing, especially since our understanding of what is empirically possible is often inductive and provisional.

The best way to go here is to return to the Postulates passage where Kant appeals to the "laws of experience with which we are acquainted." He elaborates as follows:

If one wanted to make entirely new concepts of substances, of forces, and of interactions from the material that perception offers us, but without borrowing (entlehnen) the example of their connectedness from experience itself, then one would end up with nothing but brain-figments for the [real] possibility of which there would be no indications at all, since in their case one did not accept experience as instructress nor borrow these concepts from it. (A222/B269)

The appeal to our "experience as instructress" suggests that the real possibility of the items referred to must itself agree with what the subject already knows about the world and its workings. Kant says something similar in the Discipline:

For the explanation of given appearances no other things and grounds of explanation can be adduced than those which are connected to the given appearances by already known laws of appearances. (A772/B80o, my emphasis)

In other words, even if $S$ is not able to prove that an object's possible existence agrees with what in fact is true of nature and its laws, she might be

16 Thanks to Iakovos Vasiliou, Rachel Cristy, and Avi Appel for helpful discussion of this diagram.

${ }^{17}$ I leave it as a sufficient condition here, since as we have seen there may be other ways to prove the real possibility of objects of analytic knowledge, negative knowledge, and very general positive pieces of synthetic knowledge. 
able to show that its possibility agrees with her own background knowledge of nature and its (formal and particular) laws.

Let's revisit the telepathy case with this in mind. Even if I do have experiences whose best explanation appeals to such a relation (the professional mind-reader constantly tells me precisely what I am indeed thinking), and thus even if my assent is highly probable on the grounds I possess and would cite, I am not in a position to prove that the possibility of such a phenomenon agrees with my existing background knowledge of nature and its laws. So a case like this will not satisfy the modal condition in $\left(\mathrm{v}^{* *}\right)$, even if it does satisfy conditions (i)-(iv). In the Discipline, Kant goes so far as to say that we can't even form mere hypotheses or opinions for or against such things without satisfying something like this modal condition:

Merely intelligible beings or merely intelligible properties of the things of the sensible world cannot be assumed even in opinions with any well-founded authority of reason, although (since one has no concept of either their possibility or their impossibility) they also cannot be dogmatically denied on the basis of any supposedly better insight. (A772/B80o, my emphasis)

The strategy revised in light of all this, then, would be:

Third Strategy*: $S$ is in a position to prove the real possibility of an object if $S$ is in a position to prove that its possible existence agrees with S's background knowledge of nature and its laws.

This is getting close. There is still a lingering question, however, about the notion of "agreement" involved. Kant uses "übereinkommen" or "zusammenhängen." But does this mean that the possible existence of the relevant objects must be provably consistent with our background knowledge of nature? If so, then $\left(\mathrm{v}^{* *}\right)$ would be largely impotent: logical consistency with the laws is pretty easy to come by (almost all the supersensibles and ghostly phenomena would achieve it, for instance). But then does it mean that the existence of the relevant objects must be provably compossible with what we know about nature? If so, then the condition in $\left(\mathrm{v}^{* *}\right)$ would smuggle in the presumption that we're able to discern, from the armchair, what is really compossible with what. But that was the presumption that Kant found problematic at the start! So does "übereinkommt" mean something like follows from or is entailed by? If so, then it would be hard to see how some new assents could satisfy the condition and count as knowledge. For in many cases we would presumably posit the existence of new kinds of objects or forces along with the laws governing their relations. And so their 
empirical possibility could not be entailed by what we knew about nature antecedently. ${ }^{18}$

It's often wise to go for a middle way in Kant interpretation. Here an attractive thing to say (I submit) is that Kant has in mind what we now call a positive coherence relation when he speaks of "agreement with" or "conformity to" experience and its known laws. It's not merely that the possibility of the objects referred to is consistent with our background knowledge of nature, but it's not that it is entailed by it either. Rather, there are positive coherence relations between the claim that such items are possible and our $^{19}$ background knowledge of the way the world works. As Kant says at A537/B565 "appearances... are... mere representations, which cohere according to empirical laws" [Erscheinungen ... sind . . bloße Vorstellungen, die nach empirischen Gesetzen zusammenhängen]. In other words:

Third Strategy**: $S$ is in a position to prove the real possibility of an object if $S$ is in a position to prove that its possible existence positively coheres with S's background knowledge of nature and its laws.

Talk of "proof" may sound too ambitious here, but recall that elsewhere Kant is willing to use weaker expressions such as "justify the possibility" (A259/B315). For the vast majority of our synthetic knowledge, I think this strategy describes the way the modal condition in $\left(\mathrm{v}^{* *}\right)$ is satisfied.

\subsection{Coherence and the Architectonic}

It is not unusual for coherentist accounts of a particular item of knowledge to make reference to other pieces of a subject's background knowledge. Still, in order to flesh out the proposal just sketched, we'd need to say more about what Kant takes positive coherence to consist in. My suggestion, left undeveloped here, is that this is where Kant's discussion of the importance of "systematicity" in the Architectonic (as well as the Appendix to the Dialectic and the third Critique) plays a crucial role. To know a proposition involves not just having probabilistic grounds for it and being able to cite those grounds when one assents to it. Rather, one also has to be justified in

I8 Consider in this connection Kant's discussion of why we can cognize the existence of unobservable "magnetic matter" at A226/B273.

I9 I leave the scope of "our" vague here, but note that this may make it harder for experts in a domain to acquire knowledge of certain truths than it is for others, since experts have so much more background knowledge against which to test the new proposition. 
holding that the real possibility of the objects it refers to positively coheres with one's background knowledge. ${ }^{20}$ The goal is to form an edifice (here Kant returns to his architectural metaphor) in which all the assents are

purposively united with each other as members of a whole in a system of human cognition, and allow for an architectonic to all human knowledge. (A835/B863)

This is not a mere scientific ideal - as we have seen, Kant's view is that without at least some sense of the background system, we can have "no coherent use of the understanding, and, lacking that, no sufficient mark of empirical truth; thus in regards to the latter we must presuppose the systematic unity of nature as objectively valid and necessary" (A651/B679).

I have argued that the modal condition on knowledge, interpreted in the manner of $\left(\mathrm{v}^{* *}\right)$, underwrites Kant's frequent appeals to the need for a relation to possible intuition, for objectively real (as opposed to "empty") concepts, and for the "givenness" of objects. I have also suggested that ( $\left.\mathrm{v}^{* *}\right)$ should be read along the lines of (Third Strategy**): for $S$ to be in a position to "prove" that an object is really possible is for $S$ to be able to justifiably claim that its real possibility positively coheres with her background knowledge of nature and its laws.

Here's a final case to consider: suppose you infer from the harmonious and fecund character of the natural laws as a whole to the existence of a supersensible world-author. Kant seems to regard such inferences as sound, and as providing probabilistic grounds for the conclusion (see A624/B652; A826/B854; Prol 4: 278, $T P_{2}$ 74). So (i)-(iv) are satisfied in this case. So why wouldn't this count as knowledge? ${ }^{2 \mathrm{I}}$

The question indicates that (Third Strategy**) has to be read as invoking our background knowledge of the content of the laws that take the world from one state to the next. In other words, when Kant says we should look to the "universal conditions" on experience as our instructress in systematizing our assents, he is talking not about second-order features of the laws themselves (their elegance, simplicity, etc., taken as a set), but about what the laws say regarding which event-types follow other event-types. Assent to the existence of the world-author fails to satisfy $\left(\mathrm{v}^{* *}\right)$ in this way, then, because we are never in a position to show that there are formal or particular laws whose specific content makes the possibility of a spiritual author of the world seem more or less likely. We are simply ignorant of the

20 For good discussions of this, see Geiger (2003), Bird (2006: 744-52), and Gava (2014).

2I Thanks to Michael Friedman for raising this case in conversation. 
real modal status of such a being, and so the strongest attitude we can take toward it is, as Kant explicitly tells us in the Canon, a form of belief - i.e., "doctrinal belief" (doktrinale Glaube) (A826/B854).

For similar reasons, we also can't establish positive coherence between our background knowledge of the world and the possibility of an immaterial substance, or a zombie, or a free will, or an ens realissimum, even if we have sufficient objective grounds for positing their existence. So speculative arguments that begin or end with such things (Descartes's Real Distinction argument, contemporary conceivability arguments for dualism, the ontological argument, and even Kant's own possibility proof) are ruled out of epistemic bounds, even if they satisfy (i)-(iv). This is the result we wanted, and it indicates that condition $\left(\mathrm{v}^{* *}\right)$ interpreted as a positive coherence condition is a prime candidate for inclusion in a unified account of Kantian knowledge.

\subsection{Hope, Belief, and the Canon Again}

In the Discipline, as we have seen, Kant's main goal is to dash the hopes of traditional metaphysicians by showing that their speculations about thingsin-themselves cannot result in knowledge. He also argues that opponents of traditional metaphysics overreach when they claim, equally dogmatically, that a disproof of speculative theses is in the offing. The proper attitude, in a theoretical-epistemic context at least, is suspension of assent, together with a little bravado:

Thus, think up for yourself the objections which have not yet even occurred to your opponent, and even lend him the weapons or concede him the most favorable position that he can desire. There is nothing in this to fear, and much to hope, namely that you will come into a possession that can never be attacked in the future. (A778/B806)

Kant goes on to say more about that secure "possession" in the Canon and the second Critique. Because the needs to which metaphysical speculation respond are rational and legitimate, we can reasonably hope that at least some of them will be fulfilled in a nonepistemic context. In the end Kant is famously willing to endorse both hope and full-blown "belief" (Vernunftglaube) that is based on "subjective" grounds. Most of these subjective grounds are moral:

Thus without a God and a world that is now not visible to us but is hoped for, the majestic ideas of morality are, to be sure, objects of approbation 
and admiration but not incentives for resolve and realization, because they would not fulfill the whole end that is natural for every rational being and determined a priori and necessarily through the very same pure reason. (A8I3/B84I)

But as mentioned earlier Kant also speaks in the Canon of "doctrinal" forms of belief (Glaube). The latter "must not be called practical" but rather "theoretical," and it is often directed toward traditional objects of speculation: the existence of God and "the future life of the human soul" (A826$27 / B 854-55)$. Moreover, when doctrinal belief is formed for the right "subjective" reasons - in this case as a response to our speculative need to find ultimate explanations - it is fully rational. ${ }^{22}$ This is presumably why Kant says, even in the Discipline, that "as far as the critique of the grounds of proof of the dogmatic affirmations is concerned, one can very well concede it all without thereby giving up those propositions [about the existence of God and the soul], which still have at least the interest of reason in their behalf, to which their opponent cannot appeal at all" (A74I/B769).

Interestingly, Kant thinks doctrinal belief is rational even though it doesn't meet the modal condition that he places on both opinion and knowledge. The same thing goes for moral belief:

[T] here is a ground of assent that is, in comparison with speculative reason, merely subjective but that is yet objectively valid for a reason equally pure but practical ... objective reality is given to the ideas of God and immortality and a warrant [Befugnis], indeed a subjective necessity (a need of pure reason) is provided to accept [anzunehmen] them, although reason is not thereby extended in theoretical cognition and, instead, all that is given is that their [real] possibility, which was hitherto only a problem, here becomes an assertion and so the practical use of reason is connected with the elements of the theoretical. (CPrR 5:4-5; compare A818/B846)

It is fitting that here at the end of the first Critique and the beginning of the second, Kant delivers what he promised back in the Preface - namely, an account of what knowledge is, of why we must deny knowledge of thingsin-themselves, and of how this still leaves room for both practical and theoretical varieties of belief (Glaube) regarding some such things. He reiterates this point in the Discipline: "What is in dispute here is not the topic [i.e., the doctrine] but the tone. For enough remains left to you to speak the language, justified by the sharpest reason, of a firm belief, even though you must surrender that of knowledge" (A744-45/B772-73). The Doctrine of

${ }^{22}$ For more on "doctrinal belief," see Chignell (2007a), Pasternack (2010), Gava (forthcoming), Pickering (2016). 
Method thus offers a sophisticated account of how the "elements" of cognition that were estimated in the first part of the Critique can be used, in conjunction with a disciplined "plan," to build a secure edifice of systematic knowledge, and yet still leave room for beloved metaphysics in the mode of both hope and belief. 